\title{
Urocultivo con removedor de antibióticos: mitos y verdades
}

\author{
Urine culture with antimicrobial removal: myths and truths
}

\section{Señor Editor:}

Actualmente la microbiología clínica está enfocada en el desarrollo de métodos rápidos y fáciles que brinden resultados confiables. Este desarrollo es importante para la detección de infecciones en pacientes que están recibiendo terapia antimicrobiana. Por ejemplo, a los pacientes con sospecha de sepsis se les administra antibióticos antes de obtener muestras para hemocultivos, lo que reduce la recuperación de bacterias. Ante esta situación, a inicios de los años 80 , se introdujeron dispositivos de eliminación de antimicrobianos, como las resinas adsorbentes poliméricas y catiónicas y el uso de carbón activado, diseñados para eliminar los antimicrobianos de la sangre $(1,2)$.

La infección del tracto urinario (ITU) es una de las causas más frecuentes de consulta médica, y el urocultivo es el examen microbiológico de mayor importancia para diagnosticarla (3). Algunos laboratorios clínicos privados han incorporado como parte de su metodología, el "urocultivo con removedor de antibióticos", adaptando los sistemas empleados para los hemocultivos a este fin, sin embargo, no se ha demostrado su efectividad (4).

Se han mencionado varias razones por las cuales no deben utilizarse las botellas de hemocultivo para la siembra de muestras de orina (3): a) Los agentes bloqueadores de antimicrobianos (resinas y carbón activado) han demostrado ser eficaces contra niveles séricos de antimicrobianos. En orina, estas concentraciones, pueden ser 10 a 1000 veces superiores a las concentraciones séricas (tabla 1); b) El recuento de unidades formadoras de colonias (UFC) es fundamental para el diagnóstico de las ITU; c) Algunos sistemas de hemocultivos están validados para el cultivo de líquidos biológicos estériles únicamente (según especificaciones del fabricante), sin embargo, la orina emitida por chorro medio no es un líquido estéril (5).

En nuestro país algunos estudios han probado el uso de carbón activado y resinas para la eliminación del efecto de antimicrobianos usados frecuentemente en el tratamiento de las ITU. Dalguerre (4), evaluó muestras de orina de pacientes en tratamiento con gentamicina, obteniendo más resultados positivos en las muestras pre tratadas con carbón activado. Sin embargo, las muestras de orina fueron cultivadas en caldo BHI a $37^{\circ} \mathrm{C}$ por $24 \mathrm{~h}$ y luego sembrada en medio sólido, por lo que no existe un recuento de las UFC.

Por su parte, Bisetti (6), examinó muestras de orina de pacientes tratados con ciprofloxacina, las cuales fueron procesadas de tres maneras, una con la técnica convencional, y otras dos pre tratadas con carbón activado y resina sintética, respectivamente; luego de 1 hora de refrigeración, se sembró la orina con asa calibrada de 1ul en agar Plate Count y se incubaron por $24 \mathrm{~h}$ a $37^{\circ} \mathrm{C}$, luego se realizó el conteo de UFC. Se obtuvo una mejor recuperación, con un recuento de colonias $>10000$ UFC, en aquellas que fueron pre tratadas.

1. Facultad de Farmacia y Bioquímica, Universidad de Buenos Aires. Buenos Aires, Argentina.

2. Centro de Investigaciones Tecnológicas, Biomédicas y Medioambientales, Universidad Nacional Mayor de San Marcos. Lima, Perú.

3. Hospital Nacional Docente Madre-Niño San Bartolomé. Lima, Perú.

a. Tecnólogo Médico;

b. Magister en Microbiología

Edgar Gonzales-Escalante ORCID: https://orcid.org/0000-0002-3411-9021

Javier Orlando Soto-Pastrana ORCID: https://orcid.org/0000-0001-9534-5746 
Tabla 1. Concentración sérica y urinaria de antibióticos usados frecuentemente en infecciones urinarias ${ }^{\text {a }}$.

\begin{tabular}{|c|c|c|c|}
\hline Antibiótico & Dosis, Vía & $\begin{array}{l}\text { Concentración pico sérico } \\
\qquad(\mu \mathrm{g} / \mathrm{ml})\end{array}$ & $\begin{array}{l}\text { Concentración urinaria } \\
\qquad(\mu \mathrm{g} / \mathrm{ml})\end{array}$ \\
\hline Ampicilina & 0,5 g. p.o. & 3 a 6 & 1000 a 2250 \\
\hline Cefazolina & $1 \mathrm{~g} . \mathrm{IV}$ & 188 & 700 a 2000 \\
\hline Cefuroxima & 1 g. p.o. & 14 & 1000 a 7000 \\
\hline Ceftriaxona & $1 \mathrm{~g} . \mathrm{IV}$ & 130 & 549 a 995 \\
\hline Amikacina & $0,5 \mathrm{~g} . \mathrm{IV}$ & 17 a 25 & 170 a 1720 \\
\hline Gentamicina & 0,08 g. IV & 4 a 8 & 400 a 500 \\
\hline Ciprofloxacina & 0,5 g. p.o. & 1,6 a 2,9 & 350 \\
\hline Nitrofurantoina & 0,1 g. p.o. & $<2$ & 50 a 200 \\
\hline Trimetoprima / sulfametoxazol & 0,2 g. p.o. & 2 & 70 a 100 \\
\hline
\end{tabular}

En conclusión, el "urocultivo con removedor de antibióticos" no existe como metodología estandarizada. Aquellos laboratorios que ofertan este servicio incrementan costos (suman el urocultivo más la botella de hemocultivo) y no presentan un recuento de colonias real, que es fundamental para el diagnóstico de ITU. Lo que plantea Bisetti (6), podría ser una buena alternativa, pero es necesario desarrollar un estudio con un mayor número de muestras y probar su eficacia frente a distintos antibióticos.

\section{Edgar Gonzales-Escalante ${ }^{1,2 ; a, b}$,} Javier Orlando Soto-Pastrana ${ }^{3, a}$

\section{Correspondencia:}

Edgar Gonzales Escalante

Ca. José Santos Chocano 199 Ciudad Universitaria Bellavista - Callao

Correo electrónico: egones_5@hotmail.com

\section{REFERENCIAS BIBLIOGRÁFICAS}

1. Appleman MD, Swinney RS, Heseltine PN. Evaluation of the antibiotic removal device. J Clin Microbiol. 1982;15(2):278-81.

2. Wright AJ, Thompson RL, McLimans CA, Wilson WR, Washington JA 2nd. The antimicrobial removal device. A microbiological and clinical evaluation. Am J Clin Pathol. 1982;78(2):173-7.
3. Esparza G, Motoa G, Robledo C, Villegas MV. Aspectos microbiológicos en el diagnóstico de infecciones del tracto urinario. Infectio. 2015;19(4):150-160. DOI: http://dx.doi. org/10.1016/j.infect.2015.03.005

4. Dalguerre GE. Implementación de una metodología que emplea carbón activado como removedor de antibióticos en urocultivos del Hospital Regional del Cusco MINSA. Arequipa 2014. Tesis de Título profesional de Químico Farmacéutico. Arequipa, Perú: Universidad Católica de Santa María; 2014. p: 110.

5. Hilt EE, McKinley K, Pearce MM, Rosenfeld AB, Zilliox MJ, Mueller ER, Brubaker L, Gai $\mathrm{X}$, Wolfe AJ, Schreckenberger PC. Urine is not sterile: use of enhanced urine culture techniques to detect resident bacterial flora in the adult female bladder. J Clin Microbiol. 2014; 52(3):871-6. doi: 10.1128/JCM.02876-13.

6. Bisetti CF. Evaluación del rendimiento de removedores de antibióticos en urocultivos de pacientes en tratamiento con ciprofloxacino. Tesis de Título profesional de Tecnólogo Médico en Laboratorio Clínico y Anatomía Patológica. Lima, Perú: Universidad Privada Norbert Wiener; 2018. p: 40

7. Gilbert DN. Urinary tract infections in patients with chronic renal insufficiency. Clin J Am Soc Nephrol. 2006; 1(2):327-331. DOI: https://doi.org/10.2215/ CJN.01931105

Recibido: 30/11/2019

Aceptado: 30/12/2019 